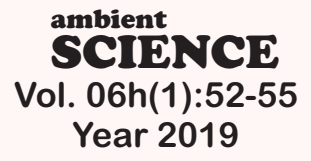

ORIGINAL ARTICLE

\title{
Intertrochanteric Fractures Treatment by DHS Verses Gamma-Nail: a Comparative Analysis
}

\section{Mohsen Khorrami, Naser Sarafan, Payam Mohammad Hoseini, Mozhgan Seyfi, Mohammad Ali Khorrami, Amin Nik kholgh}

Department of Orthopaedics and Traumatology, Ahvaz Jundishapur University of Medical Science, Ahvaz, Iran

Study Area:Ahvaz, Iran

Coordinates: $31^{\circ} 19^{\prime} 13^{\prime \prime N} ; 48^{\circ} 40^{\prime}$ o9"E

Key words: Dynamic Hip Screw, Harris Hip Score, Limb Length Discrepancy

This study, after approval by ethics committee in Ahvaz Jundishapur University of Medical Sciences (Code of Ethics: IR.AJUMS.REC.1397.880)

\section{Abstract}

An attempt was taken to compare the results of treatment of intertrochanteric fractures using Dynamic Hip Screw (DHS) and gamma-nail by a retrospective cross-sectional study on 108 male and female patients as participants aged 40 to 80 years suffering from stable and unstable intertrochanteric fractures. Participants underwent surgery in one of the two methods: DHS $(n=61)$ or gammanail $(n=47)$ and clinical evaluation in the last follow-up session, including union, lameness, and limb length discrepancy (LLD) under the supervision of an orthopedic surgeon. The Harris Hip Score (HHS) questionnaire was filled up by the patients to evaluate and compare functional recovery. Including demographic questionnaires, associated injuries (such as infection, lameness, and pain) were also tabulated. Post-surgical complications including surgical failure, deep infection, and LLD were also investigated. Ultimately, patients' ambulation status and walking status with or without auxiliary devices were evaluated. Results evidenced the higher surgery failure in the gamma-nail group (10.44\%) than in the DHS group (4.59\%). The LLD was less than $2 \mathrm{~cm}$ in both groups and was not symptomatic. Non-union rate and deep infection in the gamma-nail group were statistically higher. The mean of bleeding during surgery and duration of surgery in the gamma-nail group was also significantly lower.

1992; Mahomed et al., 1994). However, regardless of the fixation method, the overall complications of internal fixation in the elderly are still a serious concern (Walia et al., 2012). Treatment should be def ined individually and in each patient, taking into account the fracture pattern, dislocation, the degree of patient's activity before fracture, the level of autonomy of the individual in performing daily personal activities and the general health status of the patient (Center et al., 1999; Ly \& Swiontkowski, 2008; Sendtner et al., 2010). Now, there is no consensus on a suitable treatment for intertrochanteric fractures, especially in older people with underlying diseases. Further, due to variations in the results and opinions about the use of therapeutic methods in trochanteric region fractures (Jensen et al., 1980; O'Brien et al., 1995; Grimsrud et al., 2005; Zhang et al., 2005; Walia et al., 2012). The purpose of this study was to compare the results of DHS and gamma-nail treatment in intertrochanteric fractures to helpachieve optimal treatment for this type of fracture. 


\section{Methodology:}

This was a cross-sectional retrospective study, carried on 108 male and female patients aged in between 40 to 80 years with stable and unstable intertrochanteric fractures and following to Evans classification, referred to Golestan and Imam Khomeini hospitals in Ahvaz in between the year 2013 and 2017 to undergo surgery using either DHS or gamma-nail method.

The patients were contacted after collecting their demographic data from the hospitals' archives. A total of 214 cases were investigated and finally 47 patients treated with gamma neural fixation and 61 patients treated with DHS and were having complete follow-up and their radiographs which were taken preoperative and during the follow-up period. Records were compared and evaluated to know the clinical outcomes following the inclusion and exclusion criteria of the study. Initially, simple radiography was carried out as the standard test for patients, at the first, third, sixth and ninth months, and then at every six months gap continuous for two years. However, due to the clinical diagnosis of a physician and radiographic assessment, for those patients who were suspected to have avascular necrosis during the follow-up period, MRI was done to confirm the diagnosis. In order to investigate the proper union, all patients were evaluated radiographically at the time of referral and the previous graphs related to the postsurgical period and the follow-up period of the patient were also examined. Non-union was considered as lack of complete union in patients in 6 months after surgery. After referral, patients underwent clinical examinations including union, lameness, and limb length discrepancy (LLD) under the supervision of an orthopedic surgeon and these indices were determined. The Harris Hip Score (HHS) questionnaire was also filled up to evaluate and compare the performance improvement of patients. All patients were evaluated radiographically for the examination of the union. For each patient, a demographic questionnaire including personal characteristics (age and sex) and associated injuries (such as infection, lameness, and pain) were recorded separately. Post-surgical complications including surgical failure (patients undergoing revisionsurgery were considered as surgical failure and the cause of the revision was also recorded and evaluated), deep infection (based on the amount of ESR, CRP in the followup tests) and Limb length discrepancy (LLD) were also taken under consideration. Finally, patients' ambulation status and walking status with or without auxiliary devices were evaluated. The Harris Hip Score (HHS) questionnaire score was evaluated as Excellent (90-100), Good (80-89), Fair (70-79), and Poor (less than 70) patients.

Also, the fracture type by preoperative radiographs and according to Evans classification for intertrochanteric fractures was determined based on the stability or instability of fracture as follows:
Type I: Stable fracture (or without displacement, or displacement that can be reduced to a stable status) (medial cortex is healthy);

Type II: unstable fracture including a displacement fracture fixed in a non-reductive state, fracture with anteromedial cortex or reverse oblique. (Evans, 1949).

Patients were examined separately by two individuals (a specialist and an orthopedic resident). Data were collected through a structured questionnaire. After obtaining written consent from the patients who were eligible to participate in the study, they were included in this study. The inclusion criteria for the study were the stable and unstable interruptions of fracture according to Evans classification, patients treated with either DHS or gamma-nail surgery. Exclusion criteria included patients with the previous history of fracture at the site of injury, patients with pathologic fracture, diabetic patients, and patients with incomplete follow-up.

\section{Results:}

In between the two groups, no statistical difference has been observed in the demographic and clinical data of the patients. Results have been tabulated in Table-1.

Table-1: Demographic and clinical data of patients in the two groups

\begin{tabular}{|c|c|c|c|c|}
\hline Variable & & DHS $(n=61)$ & G-nail $(n=47)$ & P-value \\
\hline Age (year) & $($ Mean \pm SD $)$ & $68.51 \pm 9.19$ & $72.38 \pm 10.07$ & $>0.071$ \\
\hline Gender & Women & $37(60.66 \%)$ & $27(57.45 \%)$ & $>0.062$ \\
\hline$(\mathrm{N}, \%)$ & Men & $24(39 \cdot 34 \%)$ & $20(42.55 \%)$ & \\
\hline Fracture $t$ & ype $(\mathrm{N}, \%)$ & & & \\
\hline & Stable & $36(59.02 \%)$ & $29(61.70 \%)$ & $>0.78$ \\
\hline & Unstable & $15(75 \%)$ & $14(70 \%)$ & \\
\hline $\begin{array}{l}\text { Follow up } \\
\text { (Month) (1 }\end{array}$ & $\begin{array}{l}\text { time } \\
\text { Mean } \pm \text { SD) }\end{array}$ & $26.01 \pm 2.44$ & $29.27 \pm 1.72$ & $>0.064$ \\
\hline
\end{tabular}

In the DHS-treated group, more patients were in excellent and good grades, but no statistically significant difference between the distribution of patients in the classification defined in the HHS criteria was evidenced. The results have been tabulated in Table-2.

Table-2: Comparison of HHS scores between patients in the DHS and gamma-nail groups

\begin{tabular}{llll}
\hline Variable & DHS $(\mathrm{n}=61)$ & G-nail $(\mathrm{n}=47)$ & P-value \\
\hline Excellent (N, \%) & $18(29.51 \%)$ & $7(14.89 \%)$ & $>0.192$ \\
Good (N, \%) & $38(62.29 \%)$ & $32(68.05 \%)$ & \\
Fair (N, \%) 3(4.92\%) & $6(12.76 \%)$ & & \\
Poor (N, \%) & $2(3.28 \%)$ & $2(4.25 \%)$ & \\
Mean of HHS Score & $83.51 \pm 9.14$ & $80.38 \pm 6.57$ & $>0.182$ \\
\hline
\end{tabular}

We found no significant difference between the mean time for fracture fusion in two groups. There was a significant difference between the non-union rate of the patients in the two groups which differs statistically from each other. Although patients in the DHS group were in a better condition in terms of ambulation and less 
dependence on the use of aids while walking, in general, there was no statistically signif icant difference between the two groups. Also, there was no significant difference between the two groups in terms of total weight bearing time without using auxiliary devices. The frequency of patients with LLD in the gamma-nail group was significantly higher, but this complication was less than 2 $\mathrm{cm}$ in both groups and was not symptomatic. The rate of surgical failure in the gamma-nail group (10.44\%) was statistically higher than that in the DHS group $(4.92 \%)$ ( $\mathrm{P}$ $<0.05$ ). All 8 failed patients underwent revision surgery. There was a significant difference between the two groups in terms of deep infection, which was statistically higher in the gamma-nail group. The mortality rate in one year after surgery was also evaluated in two groups, and there were no death cases that were directly related to fixation complications. The mean of bleeding during surgery and duration of surgery in the gamma-nail group was statistically lower.

Table-3: Demographic and clinical data of patients in the two groups

\begin{tabular}{|c|c|c|c|}
\hline Variable & $\operatorname{DHS}(\mathrm{n}=61)$ & G-nail $(n=47)$ & P-value \\
\hline Nonunion* ${ }^{*}$ & $2(3.28 \%)$ & $3(6.38 \%)$ & $<0.0001$ \\
\hline Independent ambulator* & $38(62.29 \%)$ & $27(57.44 \%)$ & $>0.085$ \\
\hline Ambulator, walking aid* & $21(34.43 \%)$ & $18(38.29 \%)$ & \\
\hline Non- ambulatory* & $2(3.28 \%)$ & $2(4.26 \%)$ & \\
\hline LLD* $^{*}$ & $1(1.64 \%)$ & $2(4.26 \%)$ & $<0.041$ \\
\hline Failure rate * & $3(4.92 \%)$ & $5(10.64 \%)$ & $<0.0001$ \\
\hline Deep Infection* & $2(3.28 \%)$ & $4(8.51 \%)$ & $<0.0001$ \\
\hline Bone union time (week)** & $18.83 \pm 3.17$ & $20.64 \pm 2.14$ & $>0.058$ \\
\hline Time of full weight bearing ** & $16.03 \pm 2.59$ & $17.14 \pm 2.36$ & $>0.312$ \\
\hline Operative Blood loss $(\mathrm{ml})^{* *}$ & $210.24 \pm 24.64$ & $154.19 \pm 16.98$ & $<0.0001$ \\
\hline Operative time $(\mathrm{min})^{* *}$ & $67.20 \pm 11.02$ & $59.19 \pm 9.62$ & $<0.0001$ \\
\hline
\end{tabular}

${ }^{*}-\mathrm{N}(\%) ;{ }^{* *}-$ Mean \pm SD

\section{Discussion:}

In the study of Butt et al. (1995), the mean time for union of fracture was higher in the gamma-nail group, but the two groups did not have a significant statistical difference, which was consistent with the results of our study. Although the patients in the DHS group of our study were seen to be better in terms of ambulation and less dependence on the use of auxiliary devices during walking (62.29\% Vs. 57.44\%), there was no statistically difference between the two groups was seen. Also, there was no significant difference between the two groups in terms of total weight bearing time without using auxiliary devices. Ahrengart et al. (2002) also reported no significant difference in post-surgical walking ability in gamma-nail and DHS groups. Further, in Ahrengart et al. (2002) postoperative complications and problems in the gammanail treatment group were higher, which is also consistent with the results of the present study. The study of Butt et al. (1995) did not show a significant difference in the rate of surgical failure and wound infection in the two groups. The results of O'Brien et al. (1995) recommended the use of DHS as a treatment option for the treatment of intertrochanteric fractures rather than gamma-nail due to the low association with the risk of complications. The mean of bleeding during surgery and duration of surgery in the gamma-nail group was Statistically lower. In the study of Ahrengart et al. (2002) the rate of bleeding in the gamma-nail group was significantly lower than in our present study. The results of the study by Radford et al. (1993) reported that surgical bleeding was signif icantly less in the gamma-nail group, which was consistent with the results of the present study. In the study of Butt et al. (1995) surgical and surgical bleeding during the surgery was less in the gamma-nail group, which was consistent with the results of the present study. The limitations of this study were surgical procedures performed by several surgeons based on the location of the research, which was a university-affiliated educational hospital, as well as being retrospective and inaccessibility to all treated patients, especially in the gamma-nail group. In future studies, prospective studies with higher sample size and all surgical procedures by a surgeon with a history are recommended.

Conclusively, the significance of the difference between the clinical and radiographic results in the two groups and the higher rates of complications reported in patients treated with gamma-nail fixation, suggests that DHS, with a lower risk of postoperative complications, is a more appropriate way to treat intertrochanteric fractures. On the other hand, due to shorter surgical procedures and less bleeding during surgery in the gamma-nail group, this method can be a selective method for patients with high anesthetic risk or coagulation problems.

\section{Acknowledgment:}

We are thankful to all the particinats for their kind cooperation during the study. We also thankful to the other medical staffs for helping us in various ways to conduct this study.

\section{References:}

Aaron, J.E., Gallagher, J.C., Anderson, J., Stasiak, L., Longton, E.B., Nordon, B.E. \& Nicholson, M. (1974): Frequency of osteomalacia and osteoporosis in fractures of the proximal femur. Lancet, 1(7851):229-233.

Ahrengart, L., Törnkvist, H., Fornander, P., Thorngren, K.G., Pasanen, L., Wahlström, P., Honkonen, S., \& Lindgren, U. (2002): A randomized study of the compression hip screw and Gamma nail in 426 fractures. Clin. Orthop. Relat. Res., 401:209-222.

Bhandari, M., Devereaux, P.J., Swiontkowski, M.F., Tornetta, P., Obremskey, W., Koval, K.J., Nork, S., Sprague, S., Schemitsch, E.H. \& Guyatt, G.H. (2003): Internal fixation compared with arthroplasty for displaced fractures of the femoral neck. $J$. Bone Joint Surg. Am., 85(9):1673-1681.

Bucholz, R.W., Court-Brown, C.M., Heckman, J.D. \& Tornetta, P. (2009): Rockwood and Green's fractures in adults. Pub. by:Wolters Kluwer. P. 2296.

Butt, M.S., Krikler, S.J., Nafie, S. \& Ali, M.S. (1995): Comparison of 


\section{ORIGINAL ARTICLE}

dynamic hip screw and gamma nail: a prospective, randomized, controlled trial. Injury., 26(9):615-618.

Center, J.R., Nguyen, T.V., Schneider, D., Sambrook, P.N. \& Eisman, J.A.(1999): Mortality after all major types of osteoporotic fracture in men and women: an observational study. Lancet, 353(9156):878-882.

Evans, E.M.(1949): The treatment of trochanteric fractures of the femur. J. Bone Joint Surg. Br., 31(2):190-203.

Grimsrud, C., Monzon, R.J., Richman, J. \& Ries, M.D.(2005): Cemented hip arthroplasty with a novel cerclage cable technique for unstable intertrochanteric hip fractures. L Arthroplasty., 20(3):337-343.

Halder, S. (1992): The Gamma nail for peritrochanteric fractures. J. Bone Joint Surg. Br., 74(3):340-344.

Horowitz, B.G. (1966): Retrospective analysis of hip fractures. Surg. Gynecol. Obstet., 123(3):565-570.

Jensen, J.S., Sonne-Holm, S. \& Tøbndevold, E. (1980): Unstable trochanteric fractures: a comparative analysis of four methods of internal fixation. Acta Orthop., 51(6):949962.

Ly, T.V. \& Swiontkowski, M.F.(2008): Management of femoral neck fractures in young adults. Indian J. Orthop., 42(1):3-12.

Mahomed, N., Harrington, I., Kellurn, J., Maistrelli, G., Hearn, T., Vroemen, J. (1994): Biomechanical analysis of the Gamma nail and sliding hip screw. Clin. Orthop. Relat. Res., 304:280288 .
Ambient Science, 2019: Vol. 06h(1); 52-55 DOI:10.21276/ambi.2019.06h.1.oa12

O'Brien, P.J., Meek, R.N., Blachut, P.A., Broekhuyse, H.M. \& Sabharwal, S. (1995): Fixation of intertrochanteric hip fractures: gamma nail versus dynamic hip screw. A randomized, prospective study. Can.J. Surg., 38(6):516-520.

Radford, P.J., Needoff, M. \& Webb, J. (1993): A prospective randomised comparison of the dynamic hip screw and the gamma locking nail. Bone Joint I.,75(5):789-93.

Rosenblum, S.F., Zuckerman, J.D., Kummer, F.J. \& Tam, B.S. (1992): A biomechanical evaluation of the Gamma nail. J. Bone Joint Surg. Br., 74(3):352-357.

Schmidt, A.H., Asnis, S.E., Haidukewych, G.I., Koval, K.J. \& Thorngren, K.G. (2004): Femoral neck fractures. Instructional Course Lectures, 54(29):417-445.

Schmidt, A.H. \& Swiontkowski, M.F.(2002): Femoral neck fractures. Orthop Clin NorthAm., 33(1):97-111.

Sendtner, E., Renkawitz, T., Kramny, P., Wenzl, M. \& Grifka, J. (2010): Fractured neck of femur-internal fixation versus arthroplasty. Dtsch Arztebl Int., 107(23):401-407.

Walia, J.P.S., Gupta, A.C., Kumar, R., Sethi, S. \& Singh, S.(2012): Comparative study between standard dynamic hip screw (DHS) and cemented bipolar arthroplasty in trochanteric fracture of femur in elderly patients. $\mathrm{Pb}$. Orthop., 8(1):40-43. 